\title{
O CONTROLE DAS DOENÇAS INFECCIOSAS EMERGENTES E A SEGURANÇA SANITÁRIA
}

Eliseu Alves Waldman (*)

\section{A TRAJETÓRIA DAS DOENCAS INFECCIOSAS E SUA IMPORTÂNCIA EM SAÚDE PÚBLICA}

As doenças infecciosas acompanham o homem desde o início de sua história. Há indícios de que a persistência de agentes infecciosos entre seres humanos somente foi possível quando surgiram os primeiros aglomerados populacionais, de tamanho suficiente para a contínua circulação dessas espécies, por meio da transmissão pessoa a pessoa. A origem exata de boa parte dos agentes infecciosos não é perfeitamente conhecida, porém, a partir do momento em que houve condições para a manutenção regular desse modo de transmissão, o homem assume, com freqüência, o papel de reservatório natural de muitos microrganismos e parasitas. Além do homem, passam também a desempenhar o papel de fonte de infecção: animais infectados, alimentos contaminados e a água. As doenças infecciosas adquirem, então, condiçōes para sua ampla disseminação (Satcher, 1995).

$\grave{A}$ medida que diferentes civilizações se desenvolveram e que alguns impérios alargaram seus territórios, temos a ampliação progressiva do intercâmbio entre os continentes, criando condições favoráveis à disseminação das doenças infecciosas. Populações suscetiveis, que viviam em aglomerados humanos distribuídos em pontos distantes, mas localizados em rotas de caravanas de mercadores, eram sucessivamente atingidas por novos agentes patogênicos. Exploradores e exércitos conquistadores serviram de "vetores" para a ampla circulação de agentes infecciosos. Esporadicamente, epidemias de peste, varíola, tifo e sarampo assolavam populações, dizimando inclusive exércitos e alterando o curso da história (Satcher, 1995).

Até o final do século passado, os principais problemas de saúde pública eram a fome endêmica e as doenças infecciosas, responsáveis por elevadas taxas de mortalidade infantil e pela baixa expectativa de vida das

(") Do Departamento de Epidemiologia da Faculdade de Saúde Pública da USP. 
populações humanas. Nesta época, a falta de saneamento e as habitações insalubres constituíam ainda características das cidades; as diarréias, a varíola, a peste, a cólera e a tuberculose eram responsáveis por alta proporção dos óbitos, mesmo em países desenvolvidos (Beaglehole \& Bonita, 1997).

No correr deste século, pela melhoria das condições de vida decorrente do saneamento das cidades, do aprimoramento das habitações, da elevação da renda e do grau de instrução das populações e também pelo desenvolvimento de novas tecnologias médicas aplicadas na produção de vacinas e de antibióticos, assistimos a uma acentuada queda na morbi-mortalidade determinada pelas doenças infecciosas. Em contraposição a essa tendência, temos, a partir da década de 1920, o aumento da importância das doenças cardiovasculares, das neoplasias e da violência como causa de adoecimento e morte, especialmente após a segunda guerra mundial.

A acentuada queda da morbi-mortalidade pelas doenças infecciosas teve influência, ainda que indireta, nas modificaçōes da estrutura demográfica em boa parte dos países, caracterizadas principalmente pelo aumento da expectativa de vida, pela queda da fecundidade e pelo envelhecimento das populações. Essas transformações atingiram todo o globo, inicialmente as nações industrializadas e depois, com intensidade e velocidades distintas, as regiões em desenvolvimento (Bobadilla et al, 1993; Frenk et al, 1989).

Esse processo de transformações foi acompanhado pela modificação da principal característica das doenças infecciosas, qual seja, a de estar intimamente ligada às condições de vida definidas pela miséria e subdesenvolvimento. Hoje, as moléstias infecciosas têm seu comportamento condicionado, em boa parte, a um conjunto muito mais complexo de fatores, cujo eixo passa a vincular-se, fortemente, aos modelos de desenvolvimento econômico, às políticas de industrialização e às suas principais conseqüências, entre elas: o rápido processo de urbanização, as mudanças de hábitos das populações, as alterações ambientais nas cidades e no campo, as migrações e o aumento do intercâmbio internacional, que assume o papel de "vetor cultural" na disseminação de microrganismos (Altekruse, 1997; Fidler, 1996; Morse \& Hughes, 1996).

Tais fatores, por um lado, aceleram o processo de disseminação de microrganismos e parasitas, modificam sua interação com o homem, criando condições para a emergência e difusão de novas doenças infecciosas. Por outro, permitem o ressurgimento de doenças consideradas eliminadas. A partir do início dos anos 90 , temos, por conseqüência, o retorno das doenças infecciosas à agenda de prioridades em saúde pública, mesmo nos países desenvolvidos (CDC, 1994).

As transformações verificadas no comportamento desse grupo de doenças levam à busca de uma nova abordagem para sua compreensão. Surge então, a partir dos anos 90 , o conceito de doenças infecciosas emergen- 
tes e reemergentes, que seriam "aquelas só recentemente identificadas na população humana ou já existentes, mas que rapidamente aumentaram sua incidência e ampliaram sua distribuição geográfica" (Satcher, 1995).

Na prática, essa definição é suficientemente ampla para incluir qualquer doença infecciosa que alcance relevância em saúde pública. Numa publicação recente sobre as principais doenças infecciosas emergentes ou reemergentes dos anos 90 estão citados o hantavírus, a febre de Lassa, o dengue, a cólera, a coqueluche e a febre amarela. Vemos, portanto, lado a lado, novos e velhos problemas de saúde pública (CDC, 1994).

Vale assinalar que essa nova abordagem reflete também a preocupação das grandes potências, especialmente a partir do desaparecimento do império soviético, com o risco potencial do uso das armas biológicas por agressores externos, ou mesmo internos. Fato que justifica a ênfase que tem sido dada à organização de uma vigilância global para as doenças infecciosas emergentes e reemergentes (Kadlec, 1997).

Pelas suas implicações econômicas, políticas e militares, o controle das doenças infecciosas volta, na última década, a constituir preocupação do Estado, ganhando atualidade a busca de instrumentos adequados ao seu controle, nessa nova realidade. Com tal propósito, torna-se imperiosa a perfeita delimitação do conceito de controle a ser adotado e a identificação e aperfeiçoamento dos instrumentos a serem utilizados com essa finalidade, entre os quais poderíamos apontar: as tecnologias médicas (vacinas e antibióticos, entre outras); a vigilância de doenças infecciosas, oferecendo subsídios para a fundamentação técnica das estratégias aplicadas nas ações de controle; assim como as normas e regulamentos que fundamentam a ação da fiscalização sanitária.

Essa discussão abrange também a pesquisa e a definição de instrumentos de indução, produção e incorporação regular de novos conhecimentos, garantindo aos serviços de saúde a agilidade necessária para responder não só a riscos conhecidos à saúde da população, mas também à ocorrência de situações inusitadas.

\section{CONCEITOS DE CONTROLE DE DOENÇAS INFECCIOSAS}

Entre os conceitos mais freqüentemente utilizados, podemos citar aquele que afirma que o controle abrange uma série de atividades destinadas a reduzir a incidência e a prevalência de uma doença até alcançar um nível tal, que a mesma não mais constitua problema de saúde pública (Last, 1993) e outro, mais amplo, que o define como uma série de esforços e intervenções integrados, dirigidos à população ou a subgrupos de alto risco nela existentes, visando prevenir, diagnosticar precocemente ou tratar um agravo à saúde, assim como limitar os danos por ele gerados (Acuña \& Romero, 1984). 
Como desdobramento dos conceitos de controle, temos os de erradicação e eliminação de doenças. A erradicação é uma forma radical de controle que, de modo sucinto, pode ser definida como a extinção, por métodos artificiais, do agente etiológico de uma doença infecciosa, ou de seu vetor, sendo por conseqüência impossivel sua reintrodução em qualquer região do globo e totalmente desnecessária a manutenção da vigilância ou de quaisquer medidas de prevenção ou controle. Uma alternativa próxima à erradicação, porém mais viável, é a eliminação de uma doença infecciosa, que é atingida quando se obtém a cessação da sua transmissão em extensa área geográfica, persistindo, no entanto, o risco de sua reintrodução, seja por falha na utilização dos instrumentos de vigilância ou controle, seja pela modificação do comportamento do agente ou vetor (Evans, 1985).

\section{INSTRUMENTOS APLICÁVEIS NO CONTROLE DE DOENÇAS INFECCIOSAS}

Os instrumentos aplicados com o objetivo de controlar as doenças infecciosas são, possivelmente, mais antigos que o próprio conceito de controle, pois surgem no final da Idade Média e consolidam-se nos séculos XVII e XVIII com o início do desenvolvimento do comércio e a proliferação de centros urbanos, focalizando doenças que freqüentemente assumiam caráter epidêmico, portanto, muito antes do desenvolvimento da microbiologia, que fundamentou a teoria do contágio e permitiu o melhor conhecimento das doenças infecciosas, então denominadas doenças pestilenciais (Moro, \& McCornick, 1988).

No século XIV, a República de Veneza utilizou, provavelmente pela primeira vez, um instrumento de controle sanitário ao impedir que navios transportando doentes acometidos pela peste ancorassem em seus portos. Dessa forma introduziu a prática sistemática da quarentena ao manter isolados, por tempo determinado, indivíduos oriundos de áreas atingidas pela peste (Moro, \& McCornick, 1988).

A quarentena, juntamente com o isolamento, talvez sejam os primeiros instrumentos aplicados sistematicamente no controle da doenças infecciosas. Ambos determinam a separação de indivíduos de seus contatos habituais, assumindo caráter compulsório, visando defender as pessoas sadias, separando-as dos doentes ou daquelas que potencialmente poderiam vir apresentar essa condição. Em decorrência desses conceitos, aparecem centros especiais de isolamento, entre eles os hospitais de isolamento para varíola, tuberculose e lepra, entre outras (Rosen, 1958).

Um terceiro instrumento, que surge por extensão dos dois já citados, é o de cordão sanitário, dirigido a bairros, cidades ou áreas delimitadas e não a indivíduos. Tinha por objetivo isolar as zonas afetadas para defender as "áreas limpas" da contaminação pelas doenças epidêmicas (Rosen, 1958). 
Este conjunto de medidas de tipo restritivo, policial e com caráter muitas vezes punitivo, criava sérias dificuldades para o intercâmbio comercial entre países, que se acentuaram na segunda metade do século passado com o rápido crescimento das atividades comerciais, efetuadas principalmente através dos portos, e com o risco cada vez maior e mais freqüente de ocorrência de epidemias.

Por volta de 1880 , as pesquisas de Pasteur e de Koch permitem o desenvolvimento da microbiologia e de disciplinas afins, criando condições para a ampliação do conhecimento científico e tecnológico que permitirá avanços no campo da saúde pública, ampliando o conhecimento a respeito dos mecanismos de transmissão das doenças infecciosas e propiciando a descoberta de novos instrumentos aplicados no seu controle (Rosen, 1958).

0 acesso a esse novo elenco de conhecimentos permite, no final do século passado, o desenvolvimento de um quarto instrumento, a vigilância, definida, em seu conceito clássico, pela específica mas limitada função de, sem restringir a liberdade de locomoção, observar, pelo periodo máximo de incubação da doença sob suspeita, os individuos que tenham tido contato com pacientes atingidos pela moléstia ou que tenham transitado por regiões por ela atingidas. Seu propósito é detectar precocemente os primeiros sintomas da doença para, só então, instituir rapidamente o isolamento. Portanto, constituia uma conduta mais sofisticada do que a prática restritiva de quarentena ou isolamento (Langmuir, 1976).

A partir da década de 1950, observamos o desenvolvimento de um novo e importante instrumento, desta vez com o propósito de acompanhar sistematicamente o comportamento de doenças na comunidade, com vistas a fundamentar, aprimorar e agilizar as medidas de controle. Ele recebeu inicialmente a designação de inteligência epidemiológica (Langmuir, 1971/1976).

Esse instrumento surge no momento mais acirrado da "guerra fria", quando o uso de armas biológicas apresentava-se como um risco iminente para as grandes potências, tornando necessário o estabelecimento de sistemas de informações de morbidade e mortalidade que permitissem a identificação de uma epidemia induzida por esse tipo de arma, horas ou mesmo dias antes de tornar-se evidente para os serviços médicos e hospitalares. Tais sistemas deveriam ser liderados por epidemiologistas especialmente treinados para essa atividade (Langmuir \& Andrews, 1952).

O termo "inteligência" pode ser compreendido em seu significado mais amplo como a "capacidade para o conhecimento e compreensão" ou "habilidade para aprender a inter-relação entre fatos apresentados, usando-a como guia para ações visando determinado objetivo", ou, ainda, em seu sentido mais restrito, "obter e dispor de informações, particularmente de informações secretas". Segundo Langmuir \& Andrews (1952), a inteligência epidemiológica, tanto em seu sentido restrito, predominantemente militar, como 
em seu significado mais abrangente, "parece ser singularmente apropriada para definir a contribuição dos epidemiologistas em tempos de paz ou na guerra".

Talvez para evitar o estigma do caráter militar da palavra "inteligência", temos a sua substituição pelo termo "vigilância", que deixa de ser aplicado no sentido da observação de contatos de doentes (conceito clássico de vigilância) para ter significado mais amplo, o de acompanhamento sistemático de doenças na comunidade (conceito moderno de vigilância).

A vigilância com esse novo significado é aplicada pela primeira vez em saúde pública, em 1955, quando algumas regiões dos Estados Unidos da América (EUA) foram atingidas por uma epidemia de poliomielite, evento que ficou conhecido como o "Acidente de Cutter". Essa epidemia apresentou a particularidade de atingir crianças, assim como seus contatos, logo após as primeiras terem recebido a administração de vacina de vírus inativado (tipo Salk) contra a poliomielite. Esse episódio constituiu oportunidade ímpar para a implementação, com sucesso, de um sistema nacional de vigilância. Como resultado foi possível identificar, como causa da epidemia, a aplicação na população de dois lotes de vacina, produzidos pela indústria Cutter Laboratory. Estes lotes, por problemas técnicos, apresentavam o vírus da poliomielite parcialmente inativado, fato que indicou a necessidade de aprimoramento na tecnologia de produção desse imunobiológico, de forma a torná-lo mais seguro (Nathanson \& Langmuir, 1963).

Entre os resultados mais relevantes da vigilância da poliomielite, nessa oportunidade, tivemos a produção de novos conhecimentos a respeito de diferentes aspectos dessa doença considerados, até nossos dias, como básicos para a elaboração de estratégias para seu controle.

A vigilância no sentido de inteligência epidemiológica deve ser entendida também como o elo de ligação entre os serviços de saúde e a pesquisa, ou seja, um instrumento de identificação de lacunas no conhecimento, de indução da pesquisa e de rápida incorporação pelos serviços de saúde do conhecimento produzido, garantindo a contínua atualização das estratégias voltadas ao controle de doenças.

O uso da vigilância ampliou-se significativamente a partir do início da Campanha de Erradicação da Varíola, nos anos 60 , quando sua utilização disseminou-se por todos os continentes, propiciando sua consolidação como uma importante aplicação da epidemiologia nos serviços de saúde (Fossaert, 1974).

Apesar da diversidade de experiências, em virtude de sua aplicação em diferentes países com distintas estruturas dos serviços de saúde, a vigilância atingiu apreciável grau de delimitação em seus objetivos, fontes de dados, metodologia e procedimentos de avaliação. O nível de especificidade atingido permitiu-lhe caracterizar-se como importante instrumento de aplica- 
ção em saúde pública, seja para a agilização das ações de controle de eventos adversos à saúde, seja no apoio ao esforço permanente de aperfeiçoamento técnico das estratégias de controle de doenças.

Sua metodologia pode ser resumida pela atividade de acompanhamento contínuo e análise regular do comportamento de específicos eventos adversos à saúde em populações e pela elaboração, com fundamento no conhecimento científico, das bases técnicas que oferecem sustentação às estratégias seguidas pelos programas de controle desses eventos.

$\mathrm{Na}$ década de 1970, um instrumento, já utilizado em outras áreas de atividade humana, incorpora-se aos já utilizados na saúde pública: é a monitorização, freqüentemente confundida como sendo sinônimo de vigilância.

Talvez a forma mais sintética de distinguirmos uma da outra seja afirmar que a vigilância, por definição, acompanha o comportamento de específicos eventos adversos à saúde na comunidade, enquanto a monitorização acompanha indicadores, sejam eles de saúde, demográficos, econômicos, sociais, de qualidade ambiental ou de serviços, etc. A monitorização tem um espectro de aplicação em saúde pública bem mais amplo do que a vigilância, que pode ser resumido da seguinte forma (Waldman, 1998):

a) Analisar, continuamente, indicadores relativos à eficiência $\mathbf{e}$ efetividade dos serviços de saúde e ao desempenho dos profissionais que neles trabalham, assim como indicadores epidemiológicos que reflitam o impacto desses serviços na saúde da população.

Os resultados obtidos devem ser amplamente divulgados pois servirão tanto para o controle interno dos serviços de saúde como de instrumento de controle social do mesmo.

b) Analisar, continuamente, indicadores de qualidade de produtos de consumo humano, de tecnologias médicas, do exercício profissional na área biomédica e, ainda, de riscos ambientais, para oferecer subsídios às medidas pertinentes relativas à fiscalização e educação sanitária, e, também, identificar necessidades de pesquisas científicas ou de desenvolvimento tecnológico para a solução de determinados problemas identificados, assim como recomendar alterações na legislação específica.

Neste caso a monitorização deve ser aplicada com vistas à avaliação contínua de exposição da população a riscos determinados por consumo dos mais diferentes produtos, pelo uso de tecnologias médicas e por condições ambientais, no sentido amplo do termo. É de todo aconselhável que a(s) agência(s) responsável(eis) por essa atividade não tenha(m) atribuiçōes no campo da fiscalização sanitária, para garantir sua ind ependência.

c) Analisar, continuamente, indicadores de morbidade e mortalidade que permitam detectar alterações que expressem modificações 
nas condições de saúde da comunidade, buscando identificar suas causas e caracterizar perfeitamente seus efeitos. Identificadas as causas e caracterizados os efeitos, pode, se indicado, sugerir o desenvolvimento de sistemas de vigilância para esse(s) específico(s) evento(s) adverso(s) à saúde.

Nesse caso, a monitorização tem também por objetivo estabelecer a magnitude e o grau de prioridade de eventos adversos à saúde.

d) Analisar continuamente indicadores demográficos, econômicos sociais e de saúde com vistas a subsidiar o estabelecimento de políticas no setor social, e em especial no da saúde.

e) Coletar e analisar, sistematicamente, informações pertinentes a programas de controle de específicos eventos adversos à saúde e de seu impacto na incidência e prevalência do agravo objeto do programa, visando indicar, com base nas recomendações técnicas disponíveis ou normas já elaboradas, as medidas imediatas de controle. Nesse caso, a monitorização é um instrumento da vigilância quando aplicada no subsistema de informação para agilização das ações de controle.

Tanto a vigilância como a monitorização constituem alguns dos instrumentos mais poderosos disponíveis pela saúde pública, e o sucesso de sua aplicação por um sistema de saúde está em boa parte condicionado a sua utilização articulada com a investigação científica e o desenvolvimento tecnológico.

Por fim, vale apontar a fiscalização sanitária como importante instrumento de proteção da população contra diferentes riscos à saúde. Ela é regida por legislação específica, cujo cumprimento deve ser garantido pelo poder de polícia do Estado e, por sua vez, assegurado pelo Poder Judiciário, que deve oferecer à população a garantia do respeito aos direitos de todos os cidadãos. É um instrumento antigo em saúde pública, já utilizado no século passado com a denominação de polícia sanitária.

A fiscalização sanitária, segundo Grande (1987), deve, "por princípio, apoiar-se na ordem jurídica que emana da Constituição Nacional que, se de cunho democrático, deverá inspirar-se na dignidade dos cidadãos e das instituições por eles dirigidas, o que por conseqüência os torna responsáveis por seus atos".

A legislação específica que rege a fiscalização sanitária compreende tanto as normas de proteção individual, freqüentemente inseridas nos Códigos Penal e Civil, como as normas de proteção coletiva, freqüentemente sistematizadas nos Códigos Sanitários.

Por decorrência, a fiscalização sanitária constitui um dos instrumentos mais ágeis e eficazes disponiveis pelo Estado sempre que corretamente aplicado para a defesa da população diante de riscos, virtuais ou iminentes, de agravos à saúde. 


\section{FORMAS DE ORGANIZAÇÃO DAS AÇÕES DE CONTROLE}

Definido o conceito de controle de doenças infecciosas e apresentados os principais instrumentos aplicados com esse objetivo, cabem alguns comentários a respeito dos modos de organizarmos as ações de controle. Apresentando essa questão sinteticamente, sem nos aprofundar em aspectos particulares, podemos citar como formas clássicas e amplamente utilizadas de organização das ações de controle as campanhas e a ação programática. As primeiras ocupavam-se exclusivamente do controle de doenças infecciosas, enquanto esta última não obrigatoriamente.

No início do século $X X$, assistimos à introdução na saúde pública das campanhas, forma de organização de serviços de saúde que aplicava instrumentos fundamentados nos conhecimentos gerados pelo desenvolvimento da microbiologia e que pode ser entendida como intervenções institucionais temporárias e localizadas, planejadas e centralizadas, que partem da concepção de que é possível controlar problemas coletivos de saúde, sejam eles epidêmicos ou endêmicos, através de ações que interromperiam o processo de contaminação da coletividade pelo bloqueio da cadeia de transmissão (Soper, 1972). As campanhas, de maneira geral, ocupavam-se do controle de uma única doença ou de grupos de doenças controláveis por meio de estratégias e instrumentos semelhantes; por outro lado, não se caracterizavam pelo oferecimento de serviços regulares à população.

Desde a década de 1920, existiam em países desenvolvidos agências do Estado organizadas de forma a oferecer serviços regulares de assistência à saúde, incluindo a prevenção e o controle de doenças. Mas foi a partir dos anos 70 , com a incorporação das técnicas de planejamento na área da saúde, que tivemos o aparecimento de propostas de implantação, inclusive em países em desenvolvimento, da ação programática ou programas integrais de saúde, forma de organização dos serviços de saúde que se propunha a superar a dicotomia entre a dimensão coletiva $e$ a individual do processo saúde-doença, buscando o atributo da integralidade (Glasunov, 1983).

Os programas integrais de saúde deveriam ser elaborados visando os seguintes objetivos: a) remover as causas das doenças; b) reduzir o número e o nivel dos precursores das doenças a um estágio em que as condições adversas sejam reversíveis; c) tratar a doença clínica com vistas a prolongar a vida e limitar as seqüelas.

Esses programas podem ser implementados de diferentes formas, entre elas (Glasunov, 1983):

a) Em ações legislativas determinando a taxação de produtos nocivos à saúde, obrigando a indústria a advertir o consumidor quanto aos possiveis efeitos adversos à saúde causados por produtos comercializados, restringindo sua propaganda e divulgação, controlando a poluição do ar e do meio ambiente. 
b) Na adequação dos cerviços de saúde para que divulguem junto à população, de forma acessivel e de fácil compreensão, todas as informaçðes necessárias ao perfeito entendimento do processo saúde-doença, com especial enfase aos problemas sanitários mais relevantes na comunidade.

c) Desenvolvimento de atividades visando ao diagnóstico precoce por melo de técnicas aplicáveis, por exemplo, ao rastreamento de casos de câncer ginecológico, dlabotes, hipertensão arterial, assim como o tratamento e reabilitação de pacientes.

d) Açð̃es visando à mudança no comportamento individual das pessoas, abrangendo questões como o tabagiemo, ingestăo de bebidas alcoólicas, exercícios físicos, hábitos alimentares indispensáveis a determinados tratamentos, uso de antibióticos sem prescrição médica.

Uma crítica importante que se faz à ação programática, especialmente em sistemas de saúde que não utilizam mecanismos para a contínua atualização de seus procedimentos a reciclagem regular e seus recursos humanos, $\boldsymbol{\theta}$ a freqüéncia com que a padronizaçăo de condutas tende a se cristalizar por falta de mecanismos de avaliação contínua, tornando-se impermeável a reformulaçōes regulares promovidas com fundamento na produção de novos conhecimentos. Quando isso ocorre, a açăo programática passa a obedecer a diretrizes administrativas centralizadas, muitas vezes sujeitas a uma inércia burocrática, impedindo-a de oferecer a assisténcia integral à saúde (Gonçalves et al, 1990).

\section{O ESTADO E O CONTROLE DAS DOENGAS}

A preocupação do Estado com a proteção da saúde da população é antiga e com freqüência envolveu questōes económicas de segurança interna e externa. O acompanhamento $\theta$ a análise sistemática de estatísticas vitais, com vistas ao controle de doenças e à proteção da saúde da comunidade, tem como um de seus precursores William Potty (1623-1687). Esse cientista ingless, com formaçăo om Medicina e Economia, foi 0 idealizador da denominada "aritmética política", definida como a arte de raciocinar, com fundamento em números, os assuntos do Estado. Petty salientava a importância da saúde da população para o poder o opulência do Estado e propunha a coleta de dados demográficos, económicos, educacionais e sanitários, pois sua análise poderia trazer à luz. questões de interesse nacional (Rosen, 1958).

John Graunt (1620-1674), seguidor e amigo de Petty, desenvolveu estudos de mortalidade em Londres com os quais demonstrou a regularidade de certos fenómenos vitais e sociais. Verificou em seus estudos, por exemplo, o excesso de nascimentos do sexo masculino em relação ao feminino e 
a sazonalidade na ocorréncias dos óbitos, além de ter sido o primeiro a tentar construir uma tábua de vida (Rosen, 1958),

Na Alemanha Johan Peter Franck (1748-1821) elaborou uma vasta obra sistematizando a denominada "policia médica", abrangendo, entre outras questōes, a responsabilidade do Estado em relaç4o ao controle das doenças transmissíveis e a higiene de alimentos. Foi um dos ploneiros na análise sistemática de problemes de saúde de comunidade, elaborada com o objetivo de estudar soluções para essas questões (Rosen, 1958).

Na Inglaterra, WIIliam Farr (1807-1883) criou, em 1839, o sistema de registro de mortalidade da Inglaterra e Pals de Gales, contríbulindo com 0 aprimoramento da estatística vital. Elaborou uma das primeiras classificaçర̃es de doenças com base em trés amplos agrupamentos: a) epidémicas; b) esporádicas; c) causas oxternas ou violenta. Farr, em 1843, por meio da análise contínua de informaçós sobre mortalidade, confirma uma epidemia de influenza, desenvolvendo nessa oportunidade metodologia para a identificaçăo de excesso de mortalidade, com a qual é possfvel caracterizar a ocorrência de epidemias. Outra contribuição importante foi a implantaçăo de um sistema de coleta, análise e divulgaçăo de estatlsticas vitais, criando um instrumento dinâmico de dlagnóstico das condiçóes de saúde da comunidade (Langmuir, 1976).

No final do século $\mathrm{XIX}$, os serviços de saúde pública de grande número de países ocidentais, inclusive do Brasil, criam legislação especiflca tornando compulsória a notificação de doenças infecciosas selecionadas com o objetivo de identificar epidemias a aplicar medidas pertinentes de controle, como o isolamento e a quarentena, visando o combate de doenças como a cólera, a variola, a peste e a febre amarela (Merhy, 1985; Thacker \& Berkelman, 1988).

Em 1939, o Reino Unido cria o Serviço Nacional de Laboratórios de Saúde Pública, com o objetivo de, num esforço de guerra, estabelecer um sistema de inteligência para a identificação de epidemias causadas por agressão externa por armas químicas ou microbiológicas. Terminada a Segunda Guerra Mundial, essa rede de laboratórios é mantida com finalidades civis no campo da saúde pública. Na década de 1970, cria, junto a es\$a instituição, o Centro de Controle de Doenças Transmissíveis, com o objetivo de apoiar tecnicamente os serviços locais de saúde nas atividades de controle de doenças infecciosas (Williams, 1985).

No início dos anos 50 o Serviço de Saúde Pública dos EUA cria um programa de treinamento de médicos epidemiologistas - o Serviço de Inteligéncia para Epidemias -, existente até hoje, com o objetivo de treinar profissionais na identificaçăo e investigaçăo de surtos de doenças infecciosas. Nesta mesma época é criado o Center for Disease Control and Prevention (CDC), órgão que pode ser caracterizado como de inteligência epidemiológica, voltado à análise contínua do comportamento de doenças para 
a elaboração, com fundamento no conhecimento científico, das bases técnicas para seu controle. Entre suas principais atribuições temos a de apoiar as autoridades locais de saúde na investigação de epidemias de doenças conhecidas ou não, com o objetivo de identificar seu agente etiológico, formas de transmissão e fatores e grupos de risco (Brachman \& Music, 1989; CDC, 1999).

\section{COOPERAÇÃO E REGULAMENTOS INTERNACIONAIS PARA O CONTROLE DE DOENÇAS INFECCIOSAS}

Existe uma tradição de cooperação entre os Estados para o controle das doenças infecciosas por meio de tratados internacionais. Mais recentemente, esse esforço tem contado com o apoio da Organização Mundial da Saúde (OMS). Um exemplo é a criação, em 1965, da Unidade de Vigilância Epidemiológica da Divisão de Doenças Transmissíveis da Organização Mundial de Saúde (Thacker \& Berkelman, 1988). Em 1970, a Organização Panamericana de Saúde, em seu Plano Decenal de Saúde das Américas, recomenda a seus membros a manutenção de sistemas de vigilância adequados à estrutura sanitária de cada país, com o objetivo de conhecer permanentemente os caracteres epidemiológicos de um elenco de doenças infecciosas de notificação compulsória e dos fatores que os condicionam, para permitir medidas adequadas e oportunas de controle (Fossaent, Llopis, Tigre, 1974).

Mais recentemente a literatura a respeito das doenças infecciosas emergentes e reemergentes enfatiza a natureza global desse problema, facilmente perceptível a partir da definição anteriormente apresentada e ainda pelo fato de poder emergir de qualquer local do planeta e, rapidamente, disseminar-se por meio do comércio ou de viagens (Findler, 1996). A necessidade de colaboração entre os países salienta a importância de regulamentos internacionais, especialmente a partir da tendência de globalização dos mercados e da contínua introdução de novas tecnologias de comunicação e na produção de insumos, produtos e serviços.

Como já salientado, o processo de globalizaçăo afeta a saúde pública por vários mecanismos; entre eles possivelmente o de maior importância para a segurança sanitária de produtos de consumo humano seja a intensificação da natureza global da cadeia de produção e venda de alimentos. A integração política e econômica, com livre trânsito de mercadorias e de pessoas, tem apresentado resultados algumas vezes positivos para o desenvolvimento e enriquecimento dos povos, mas cria obstáculos para o controle das doenças infecciosas.

Essas mudanças na economia internacional têm intensificado a competição por meio da diminuição de custos dos produtos, determinando, com freqüência, pressōes visando a redução de gastos governamentais para di- 
minuição de tributos, atingindo inclusive programas de saúde pública, fragilizando as agências responsáveis pela prevenção e controle de doenças infecciosas, deteriorando a infra-estrutura dos serviços, fato verificado tanto em países industrializados como nos em desenvolvimento (Berkelman et al, 1994).

Recentemente a OMS criou uma nova unidade voltada à prevenção e controle de doenças infecciosas emergentes com o objetivo de mobilizar rapidamente recursos ao primeiro sinal de epidemia, especialmente quando existir o risco de assumir caráter pandêmico. Por sua vez a Organização Pan-americana de Saúde elaborou um plano para o controle de doenças infecciosas emergentes nas Américas.

O Regulamento Sanitário Internacional (RSI) adotado em 1951 e administrado pela OMS representa o mais importante instrumento legal relativo ao controle de doenças infecciosas, abrangendo procedimentos visando limitar a transmissão de doenças infecciosas por meio do tráfego internacional, incluindo, por exemplo, a desinsetização, a desinfecção de navios e de aeronaves, mas aplica-se somente para a peste, febre amarela e cólera. À semelhança dos demais regulamentos internacionais, o RSI deve ser implementado por leis nacionais e por definições de políticas. Tal fato e a necessidade de instrumentos legais para atuar de forma mais ampla na prevenção e controle das chamadas infecções emergentes têm levado a esforços da OMS no sentido de revisar, atualizar e ampliar a abrangência desse regulamento (Findler, 1996).

Existem sérios obstáculos para atingir adequada efetividade na aplicação desse regulamento e para ampliar sua abrangência em face das dificuldades de sua compatibilização com os interesses relacionados à soberania dos Estados. Por outro lado, o bom desempenho de ações internacionais no controle de doenças infecciosas pressupõe a existência de uma rede internacional de vigilância e controle dessas doenças, o que implica uma boa infraestrutura de serviços de saúde, além do apoio de centros de pesquisa e recursos para formação e treinamento regular de pessoal especializado, requisitos pouco viáveis para países em desenvolvimento e impossíveis de tornar-se obrigatórios por regulamento internacional (Findler, 1996).

Outros aspectos que tornam complexas a discussão $\theta$ a implementação de um novo RSI é o fato de o controle da doenças infecciosas emergentes ser multisetorial, abrangendo entre outras questões polêmicas aquelas relacionadas ao comércio internacional e às legislações nacionais relativas ao meio ambiente e à produção e industrialização de alimentos.

\section{SEGURANÇA SANITÁRIA E DOENÇAS INFECCIOSAS}

Talvez possamos afirmar que, das doenças infecciosas, as de transmissão respiratória ainda são aquelas que oferecem maiores riscos à huma- 
nidade. A vulnerabilidade a esse grupo de infecções vem-se acentuando pelo processo acelerado de urbanizaçăo e pelo número crescente de grandes aglomerados populacionais em todos os continentes. O risco potencial de uma pandemia de gripe como a ocorrida em 1918, quando, segundo estimativas, morreram, em questão de meses, cerca de 25 milhões de pessoas em todo o mundo, 6 algo contra o qual pouco poderemos fazer para evitar ou diminuir significativamente sous efeitos.

Nas áreas mais desenvolvidas do globo, excluidas as infecções respiratórias, verificamos o aumento progressivo da importância das infecções decorrentes do intercâmbio internacional, do uso de novas tecnologias médicas, destacando-se os antibióticos, técnicas invasivas de diagnóstico e utilizaçăo terapêutica ou profllática de sangue o hemoderivados, ou, ainda, transmitidas por produtos de consumo humano introduzidos no mercado nas últimas decadas, especialmente os alimentos industrializados (CDC, 1999; $\mathrm{Na-}$ thanson at al, 1997; Aubry-Damon \& Courvalin, 1999).

Especialmente nas últimas duas décadas, a ocorrência de surtos inusitados de doenças infecciosas praticamente foi incorporada ao cotidiano dos povos desenvolvidos, isso porque a modificação do perfil de comportamento dessas doenças ocorreu mais precocemente nesses países, mas também por possuírem serviços de vigilância ḅem estruturados e equipes de epidemiologistas adequadamente treinadas para a identificação $\theta$ investigação desses eventos.

Para citarmos alguns exemplos de surtos inusitados associados aos fatores assinalados, podemos apontar a epidemia de encefalite ocorrida em 1999, na área urbana da cidade de Nova York, causada por um vírus que normalmente circula no continente africano no Oriente Médio. Nem todos os fatores envolvidos nessa epidemia gão perfeitamente conhecidos, mas esse agente foi, possivelmente, introduzido em território norte-americano por meio do intercâmblo internacional de pessoas ou aves infectadas (CDC, 1999).

Em 1986, fol identificada na Inglaterra uma epidemia de doença neurológica desconhecida, acometendo rebanhos de gado em diversas regiões do pais. Essa doença recebeu a denominação de encefalite espongiforme bovina ou doença da vaca louca, cujo agente etiológico ó um agente infeccioso ainda não descrito, os prions. As investigações dessa epidemia verificaram que a contaminação desses rebanhos bovinos estava associada à introdução na ração dos animais de proteina de carneiros, cujos rebanhos, na Inglaterra, sofrem endemicamente de doença neurológica semelhante. Na década de 90, surgem na Europa casos humanos de uma doença neùrológica semelhante à síndrome de Creutzfeldt-Jacob, associados ao consumo de carne bovina originária de rebanhos atingidos pela referida encefalite bovina (Nathanson et al, 1997). As repercussões dessa questão em termos de saúde pública $\Theta$ de relaçōes económicas internacionais têm sido amplamente discutidas na imprensa. 
Podemos citar ainda, duas epidemias causadas por salmonelas. Uma delas, atingindo lactentes, foi determinada pela contaminaçăo de leite em pó, produzido em determinada indústria, por Salmonella newbruawick, em decorréncia de erro tecnologico no processo de llofilizaçăo (Thacker et al, 1983). A outra, vitimando adultos com forma grave de gastroentroenterite determinada por Salmonella nowport, multiresiatente a antimicrobianos, veiculada por carne industrializada originária de rebanhos alimentados por ração adicionada de quantidade excessiva de antibióticos de largo espectro ( $\mathrm{Holm}$ berg of al, 1984).

A identificação dessas epidemias constitui exemplos da aplicação de sistemas de vigilância na segurança sanitária. Em todas essas epidemias, a vigilância mostra-se como instrumento indispensável de apoio técnico à elaboração ou atualização de legislação específica, tornando mais eficiente a fiscalização sanitária. Mostra também sua utilidade na rápida identificação de novas doenças ou de alteração no comportamento de moléstias já conhecidas.

Nos últimos anos, o controle sanitário de produtos de consumo humano, de riscos ambientais e da qualidade de serviços de saúde vem-se tornando cada vez mais amplo e complexo, abrangendo questóes técnicas de espectro multidisciplinar. Portanto, deve ser implementado de forma coordenada $\theta$ integrado por um conjunto de agéncias adequadamente equipadas e contando com pessoal especificamente treinado para atuar nesse campo.

Dois aspectos atuais do comportamento das doenças infecciosas são de especial interesse à segurança sanitária: i) as condiçő̉es favoráveis para a emergência e disseminação de agentes infecciosos at aqui desconhecidos ou já conhecidos mas que apresentam comportamento modificado, dificultando sua identificaçă̌o e controle; ii) o fato de essas doenças apresentarem-se com maior frequência na comunidade na forma de surtos constituídos de número reduzido de casos ou um número relativamente elevado, mas distribuldo no tempo e no espaço de maneira dispersa.

Nessas condições é indispensável a elaboração e contínua atualização de normas e padrões de qualidade de produtos, insumos e serviços, assim como mecanismos de avaliaçuo de seu cumprimento e efetividade. Assume a mesma importancia a existência de recursos humanos treinados especificamente para a identificaçăo e investigaçăo de surtos com vietas à rápida caracterização do agente etiológico, modos de transmissăo $\theta$ delimitação de grupos e fatores de risco, informações indispensáveis ao estabelecimento de estratégias ágeis eficientes de controle. $O$ sucesso dessas equipes está condicionado, em boa parte, a um adequado apoio diagnóstico e a uma estreita colaboração com equipes de pesquisa multidisciplinar.

A utilizaçăo de instrumentos adequados para a identificação precoce de doenças infecciosas ainda desconhecidas ou que por diferentes mecanis- 
mos alteraram seu comportamento clínico elou na forma de atingir populações humanas, tornando ineficientes as estratégias de controle até aqui aplicadas, é essencial para minimizar as taxas de morbi-mortalidade, diminuir o período e a freqüência de incapacidade e as perdas econômicas decorrentes das doenças infecciosas emergentes. A vigilância em saúde pública - coleta regular e sistemática de dados relativos ao comportamento de doenças na comunidade, acrescida da análise com fundamento no conhecimento científico e ampla disseminação dessa informação analisada, acrescida ainda das recomendações pertinentes para seu controle - é a pedra angular para a necessidade de um sistema ágil de identificação/reposta a riscos à saúde da comunidade (Waldman, 1991).

\section{REFERÊNCIAS BIBLIOGRÁFICAS}

Acuña, $D$. L. e Romero, A. "Perspectivas de la investigación epidemiológica en el control y vigilancia de las enfermedades", Salud publ. México, 1984, 26:281-296.

Altekruse, S. F.; Cohen, M. L. e Swerdlow, D. L. "Emerging foodborne diseases", Emerging Infectious Diseases, 1997, 3(3):285-293.

Aubry-Damon e Courvalin, $P$. "Bacterial resistence to antimicrobial agents: selected problems in France, 1996-1998", Emerging Infectious Diseases, 1999, 5(3):198-206.

Beaglehole, R. \& Bonita, R. "Public health at the crossroads", Cambridge, Cambridge University Press, 1997.

Berkelman, R. L.; Bryan, R. T.; Osterholm, M. T.; Leduc, J. W. e Hughes, J. $M$. "Infectious disease surveillance: a crumbling foundation", Science, 1994, 264:368-370.

Binder, S.; Levitt, A. M.; Sacks, J. J. e Hughes, J. M. "Emerging infectious diseases: Pulbic health issues for the 21 st century", Science, 284, 1999, (5418):1311-1313.

Bobadilla, J. L.; Frenk, J.; Lozano, R.; Frejka, T. e Stern, C. "The epidemiologic transition and health priorities", apud Jamison, $D$. T., in Disease control priorities in developing countries, Oxford Medical Publications, Oxford University Press, 1993, pp. 161/187.

Brachman, P. S. e Music, S. I. "Epidemiology training and public health practice", Epidem. Infect., 1989, 102:199-204.

Center for Disease Control and Prevention, "Addressing emerging infectious disease threats. A prevention strategies for the United States", 1994.

Center for Disease Control and Prevention, "Highlights in public health, Landmarks articles from the MMWR 1961-1996", 1999. 
Center for Disease Control and Prevention, "Outbreak of West Nile-Like viral encephalitis", New York, MMWR, 1999, 48(38):845-849.

Evans, A. S., "The eradication of communicable diseases: myth or reality?", Amer. J. Epidem., 1985, 122:199-207.

Findler, D. P., "Globalization, international law, and emerging infectious diseases", Emerging Infectious Diseases, 1996, 2(2):77-84.

Fossaert, D. H.; Llopis, A. e Tigre, C. H., "Sistemas de vigilância epidemiológica", Bol. Ofic. Sanit. Panamer, 1974, 76:512-525.

Frenk, J.; Bobadilla, J. L.; Sepulveda, J. e Cervantes, M. L., "Health transition in middle-income countries: new chalienges for health care", Health Policy and Planning, 1989, 4(1):29-39.

Glasunov, I. S.; Grabauskas, V.; Holland, W. W. e Epstein, F. H., "An integrated programme for the prevention and control of noncommunicable diseases", J. chron. Dis., 1983, 36:419-426.

Gonçalves, R. B. M.; Schraiber, L. B. e Nemes, M. I. B., "Seis teses sobre ação programática em saúde", apud Lima, A. M. M.; Sala, A.; Cąstanheira, E. R. L.; Ayres, J. R. C. M.; Schraiber, L. B.; Gonçalves, R. B. M. e Teixeira, R. R., Programação em saúde hoje, São Paulo, Hucitec, 1990, pp. $35 / 64$.

Grande, E., "La fiscalización", apud Mazzafero, V. E. in "Medicina en salud pública", Buenos Aires, El Atheneo, 1987, pp. 599/604.

Holmberg, S. D.; Osterholm, M. T.; Senger, K. A. e Cohen, M. L., "Drugresistent salmonella from animals fed antimicrobials", N. Engl. J. Med., 1984, 311:617-622.

Kadlec, R. P.; Zelikoff, A. P. e Urtis, A. M., "Biological weapons control, Prospects and implications for the future", JAMA, 1997, 278(5):351-356.

Langmuir, A. D. e Andrews, J. M., "Biological warfare defence. 2 - The Epidemic Inteligence Service of the Communicable Disease Center", Amer. J. publ. Hlth, 1952, 42:235-238.

Langmuir, A. D., "Evolution of the concept of surveillance in the United States", Proc. roy. soc. Med., 1971, 64:681-684.

Langmuir, A. D. e Willian, Farr, "Founder of modern concepts of surveillance", Int. J. Epidem., 1976, 5:13-18.

Last, J. M., "A dictionary of epidemiology", New York, Oxford University Press, 1993.

Merhy, E. E., "O capitalismo e a saúde pública", Campinas, Papirus, 1985. 
Moro, M. L. e McCornick, A., "Surveillance for communicable disease", apud Eylenbosch, W. J. e Noah, N. D., "Surveillance in health and disease", Oxford, Oxford University Press, 1988, pp. 166/182.

Morse S. S. e Hughes, J. M., "Developind and integrated epidemiologic approach to emerging infectious diseases", Epidemiol. Rev., 1996, 18(1):1-3.

Nathanson, N. e Langmuir, A. D., "The Cutter incident. Poliomyelitis following formaldehyde-inactivated poliovirus vaccination in the United States during the spring of 1955", I. Background. Amerlcan Journal of Hygiene, 1963, 78:16-28.

Nathanson, N.; Wilesmith, J. e Griot, C., "Bovine spongiform encephalitis (BSE): Causes and consequences of a commun source epidemic", Amer. J. Epidemiol., 1997, 145(11):959-969.

Plotkin, B. J. e Kimball, A. M., "Designing an international policy and legal framework for the control of emerging infectious disease: first steps", Emerging Infectious Diseases, 1997, 3(1):1-9.

Rosen, G., "A history of public health", New York, MD Publication, 1958.

Satcher, $D$., "Emerging infectious: getting ahead of the curve", Emerging Infectious Diseases, 1995, 1(1):1-6.

Soper, F. L., "Hacia la conquista de la salud", in Organización Panamericana de la Salud, Washington D. C., Plueblicación científica, 1972, pp. 353/ 371.

Thacker, S. B. e Berkelman, R. L., "Public health surveillance in the United States", Epidem. Rev., 1988, 10:164-190.

Thacker, S. B.; Choi, K. e Brachman, P. S., "The surveillance of infectious diseases", J. Amer. med. Ass., 1983, 249:1181-1185.

Waldman, E. A., "Usos da vigilância e da monitorização em saúde pública", Informe Epidemiológico do SUS, 1998, 5(3):87-107.

Waldman, E. A., "Vigilância como prática de saúde pública", Tese de Doutorado, Universidade de São Paulo, 1991.

Williams, R. E. O., "Microbiology for the Public Health", London, Public Health Service, 1985. 